\title{
A critical reflection on improving effective team communication
}

Hua Yang*

Department of Otorhinolaryngology-Head and Neck Surgery, Nanfang Hospital,

Southern Medical University, Guangzhou, Guangdong 510515, China

Received: 21 October 2018; Accepted: 22 December 2018; Published: 20 March 2019

Abstract: Objective: This paper aims at critically reflecting on the author's personal experience in the context of communication within a nursing team and exploring relevant existing constraints with a view to improving practice and achieving more effective outcomes in team communication.

Methods: Critical emancipatory reflection is used to evaluate and interpret the author's practice. Smyth's model serves as a framework to guide critical reflection step by step in this paper. Relevant theoretical perspectives help to make sense of the author's performance in terms of team communication.

Results: It is identified via emancipatory reflection that the author endorses the ideas of equality, respect, trust, and collaboration, which were formed and established during the process of professional socialization. However, different constraints, such as sociocultural, historical, political, and personal factors, impede the author from performing more effectively in terms of team communication. Reconstruction provides the author opportunities to take actions to rectify constraints and avoid the reemergence of previous situations in the future.

Conclusions: Reflection is an effective way to gather knowledge and develop comprehensive understanding of practice. Alternative actions for effective team communication are recommended, including formulating ground rules for discussion, guiding nurses in the correct way, transforming conflicts within a team, being an active and reflective listener, and motivating nurses to actively create.

Keywords: critical emancipatory reflection $\bullet$ Smyth's model • team communication • critical social theory • professional socialization • constraints (c) Shanxi Medical Periodical Press.

\section{Introduction}

Reflecting on previous experience is an important ability for nurses to recognize our own strengths and weaknesses, empowering us to generate an alternative and enhance future performance. ${ }^{1}$ Compared with the process of simply questioning our practice using the questions "how" and "why", critical emancipatory reflection is regarded as a more complex task, which requires us to identify the factors that constrain effective practice through analysis of our work activities in a deep, systematic, and direct way. ${ }^{2}$ The process of critical emancipatory reflection enables us to explore, analyze, interpret, and theoretically test our own practices. In this paper, I will critically reflect on my personal experience in the

How to cite this article: Yang $\mathrm{H}$. A critical reflection on improving effective team communication. Front Nurs. 2019; 1: xx-Xx. 
context of communication within a nursing team, getting a deep and broad understanding of my thoughts and actions, and developing a new independent perspective to make a difference in my future career and achieve more effective outcomes in team communication.

\section{Methods}

Critical emancipatory reflection has been chosen to help me critically evaluate my practice and interpret my role and social obligation in my workplace, without being limited by taken-for-granted assumptions and oppressive forces. ${ }^{3}$ In this paper, Smyth's model has served as a framework to guide critical reflection step by step, including the stages of describing, informing, confronting, and reconstructing. ${ }^{4}$ Relevant theoretical perspectives, such as hegemony, socialization, and critical social theory, are also integrated into the processes of critical emancipatory reflection to help me make sense of my practice issue.

\section{Results}

\subsection{Describe}

The practice issue reflected in this paper is regarding my performance in the context of team communication. As the head nurse of my department with $>20$ years of clinical nursing experience, I have found that effective teamwork is a guarantee for achieving organizational goals, while communication is like a bridge that promotes mutual understanding and collaboration between team members. ${ }^{5}$ During my working period, I spend a lot of time in communicating with various people, particularly with nurse colleagues. I tend to communicate with them in a friendly way, listening to their feelings and opinions, respecting their perspectives, and trying to make them accept my advice on their own initiative. I often reach my desired results with one-to-one conversations. ${ }^{6}$

However, I find that communication within a team is not always as efficient as expected. ${ }^{7}$ For example, when implementing new changes in the working protocol of nurses, sometimes, it had become difficult to persuade some nurses to agree with my decision, although I had discussed the feasibility of these changes with senior nurses before declaring them in a nursing team meeting. Typically, no helpful and feasible suggestions were proposed by the nursing staff during the meeting, except for emphasizing various difficulties. Hence, I had to force them to accept these alterations finally. Such a circumstance has happened more than once. I felt a little bit frustrated and dissatisfied with results such as these since we did not reach a consensus through team communication.

\subsection{Inform}

It seems as if I value other medical staff's views and am willing to hear from others before making decisions. I asked for opinions before team meetings and also created an open communication environment during meetings, allowing everyone to contribute and share their opinions or express their perceptions. ${ }^{8}$ However, I only discussed with several nurses and did not provide necessary information equally to all nurses before meetings, which was not good for promoting team communication and achieving satisfactory outcomes. Moreover, I clearly realize that conflict is inevitable within a team, particularly when team members with different backgrounds, experiences, personalities, and goals work together..$^{9,10}$ It seems as if I believe that effective communication in teams is conducive to dispelling any misunderstanding between persons. ${ }^{5}$ Nevertheless, unexpected situations still occurred occasionally when different voices arose during meetings. By forcing my nursing colleagues to accept my decision, it seems as though I act according to my belief that the utilization of rights is a direct and effective way to deal with the conflicts within a team. This does not mean that I advocate hegemony. ${ }^{11}$ Indeed, the overuse of hegemony is inclined to heighten distrust among staff members, which increases the difficulties in management and is unfavorable to collaboration and teamwork. ${ }^{12}$ With years of management experience, I am confident that I possess the ability to view things from a higher perspective than other nurses and make an appropriate decision to improve nursing practice and achieve team goals. I expect my colleagues to show enough respect for me and trust my judgments and decisions. My role and position in the nursing team provide me with the corresponding rights and responsibilities to make the final decision. ${ }^{13}$

From my practice in terms of communication in a team, I can see that I value the ideas of equality, respect, trust, and collaboration. ${ }^{14}$ These values come from my harmonious family, as well as my personal life and work experiences. When I was young, my parents taught me that mutual respect and mutual trust were essential to interpersonal communication. ${ }^{15}$ As I grew up from a novice to a professional, I gradually concluded that respect, trust, equality, and collaboration were the four key elements for successful teamwork. ${ }^{16}$ According to Lai and Lim, ${ }^{17}$ the process of professional socialization includes the internalization into a person's own behavior those values most pertinent to his/her profession and self-awareness. I usually actively embody all these values in my interaction with medical staff, patients, and other service workers during most of my working time. I find that the ideas of equality, respect, trust, and 
collaboration help me improve my work efficiency and maintain a good relationship with my colleagues.

Furthermore, being the nursing leader, I embody these values and present myself as a role model of desirable attitudes and behaviors for nursing colleagues to emulate. ${ }^{18}$ All these values are widely spread in my department, which is beneficial in fostering a harmonious and mutually supportive work environment. The ideas of equality, respect, trust, and collaboration bring positive effects for everyone and serve both nursing colleagues and my own interests. Holding the same values shortens the distance between my colleagues and me. The good relationship between us makes it easy for me to communicate with them like a friend, neglecting the gap caused by the hierarchy of authority and power. ${ }^{19}$ Nurses also feel free to talk with me, seeking my suggestions, expressing their true perspectives, and even complaining about the unfair treatment they encounter. Good communication is crucial for good teamwork, consequently influencing the delivery of safe and effective patient care. ${ }^{5,20}$ These ideas also serve my patients and other medical staff's interests. These values help me to make decisions and act ethically when interacting with others. For example, I continue to endorse these values while taking care of my patients, which promotes the establishment of mutual trust and a collaborative relationship between us. Actually, my patients prefer that I inquire about their diseases and treatments since I can provide them with relevant knowledge in detail using just plain language, which renders the medical professional knowledge more understandable. ${ }^{21}$

\subsection{Confront}

However, my personal experiences in the context of communication have disclosed that the outcome of communication within a team is not always as effective as communication between individuals. Why is there such a difference? What are the reasons that cause me to use my rights and impose my decision on nursing staff? Have the ideas of equality, respect, trust, and collaboration been fully embodied in the process of team communication? I constantly ask myself these questions after learning of critical emancipatory reflection. ${ }^{3}$ Emancipatory reflection enhances my awareness of a sense of personal power and agency, allowing me to examine the distortions that arise in my interpersonal communicative action and to critique the dominant relationships in my work setting and the constraints within my practice. ${ }^{3}$

To be honest, I must admit that, sometimes, the values of respect, trust, equality, and collaboration are not obviously embodied in my practice. Looking back on my earlier life and work experiences, I regard myself as a considerate person and as one who would like to think from the standpoint of other people before doing things or making decisions. I am prone to analyzing certain issues from different angles. My husband says that I have always considered the pros and cons when discussing an issue, which makes it difficult for others to argue against me. Nevertheless, due to these personality characteristics, sometimes, I become a little selfrighteous and ignore the real views of others, which goes against the ideas of respect and equality. ${ }^{22,23}$

Taking the above-mentioned practice issue as an example, I did not ask junior nurses for their opinions before the meeting since I took it for granted that senior nurses could put forward more constructive advice than could junior nurses, according to my previous experience. From my actions, I could not deny that I did not show equal respect to nurses at different hierarchical levels. Furthermore, although I realized that implementing new changes would be a great challenge to everyone, I did not share the necessary information to all nurses in advance. I thought that I had made an appropriate and feasible decision through careful consideration and trade-offs. ${ }^{24}$ Information sharing is considered essential for team decision-making and team performance improvement. ${ }^{25}$ Without advance information, it was difficult for nurses to accept great changes or propose useful suggestions within a short time. In general, every individual is fond of appraising things or issues in the context of his or her own interests and standpoints. ${ }^{26}$ Nurses paid more attention to the difficulties or problems they might encounter during the implementation process, while I focused more on the results accruing from the implementation of changes, which is related to the achievement of organizational goals. Disagreement and complaint inevitably occurred during team communication. My responsibilities and my rights, which are granted by the hospital, prompted me to make the final decision regardless of disagreement, although in my innermost thoughts, I expected that the decision would be unanimously approved via team communication. ${ }^{27}$

The differences in opinion did not affect my relationship with my nursing colleagues. In fact, they expressed an understanding of my actions and my decisions, cooperating with me and supporting my work as always. This could be attributed to the shared ideas of respect, trust, equality, and collaboration between us. Similarly, I could understand their feelings while accepting changes reluctantly or under compulsion, as similar situations had happened to me. Sometimes, my leaders, in the same way, forced me to agree with their decisions when our opinions were divided. I regard this phenomenon as one of the sociocultural constraints in my workplace; in other words, subordinates should respect and obey their superiors. ${ }^{3}$ Due to the hierarchical structure of management, supervisor-subordinate relationships are 
perceived as the dominant power relations in my hospital. According to Leader Member Exchange Theory (LMX), from the employees' point of view, a high-quality supervisor-subordinate relationship is essentially characterized by a high level of mutual respect, trust, and support. ${ }^{28}$ However, this type of relationship might lead to increase in the discretionary power of supervisors and, in turn, reduction in the autonomous power of subordinates, negatively affecting subordinates' affective commitment. 28,29 The supervisor-subordinate relationship, as a sociocultural constraint operating between nursing colleagues and me, determines the different positions and roles of each person during team communication. We hold different levels of power in accordance with our structural positions and personal experiences. ${ }^{30}$ The cultural conventions in the context of respect and obedience within the supervisor-subordinate relationship still influence and control our interpersonal communication methods.

Reflecting on my practice with regard to team communication, I have recognized that other kinds of constraints exist in my workplace. Historically, I have enjoyed more duty-related power than other nursing staff since I was appointed as the head nurse in my department. I have got used to setting the tone for team communication and have become the ultimate decision maker within the nursing team, while my nursing colleagues have been habituated to obedience and subservience to their supervisors, influenced by the constraints of history. I consider that the political constraints are demonstrated in the different levels of power and prestige possessed by a nurse manager and a general nurse. The organizational structure and politics of my hospital empower me with the rights and responsibilities corresponding with my leadership position, which requires me and also inspires me to guide nursing staff, taking actions to continuously improve the quality of nursing care.

The personal constraints affecting my practice are related to my leadership style and the ability of guidance during team communication. Over the years, I have engaged myself with responsibility in my work and accumulated a wealth of work experiences. I am dedicated to my job and aim to become a transformational leader, establishing supportive environments with adequate working conditions for nurses and empowering them to create and innovate so as to provide highquality and safe care for patients. . $^{31,32}$ However, due to the gap in age and work experience, sometimes, I adopt a paternalistic leadership style unconsciously. ${ }^{33}$ In particular, when a task is considered too difficult for nurses or beyond their capabilities, I might arrange everything for them or give them specific instructions. Even if they put forward some proposals, I would evaluate or judge them according to my own criteria, because I do not want to take detours or make mistakes. Nevertheless, it is said that a failure usually proves to be a crucial stepping stone toward innovative success. ${ }^{34}$ The paternalistic leadership style is not good for encouraging and motivating nurses' innovation since it deprives nurses the opportunities to learn from failures. Moreover, I lack the skills that promote effective team communication. For instance, I fostered an open communication environment to encourage nurses to express their opinions freely. But sometimes, the discussion was off-topic and I did not get the meeting back on track in time. In addition, the lack of listening skills prevents me from being a good listener during team communication, which is regarded as a key characteristic of an effective leader. ${ }^{35}$

\subsection{Reconstruct}

Emancipatory reflection allows me not only to criticize myself but also to reconstruct myself. The fundamental purpose of critical reflection on my practice issue is to make a change in my future career so as to improve the efficiency of team communication. By systematically analyzing my previous practice, I have become aware that there are contradictions in my values and my behaviors. I uphold the values of equality, respect, trust, and collaboration; however, my actions sometimes run contrary to these ideas. Certain sociocultural, historical, and political factors, ${ }^{3}$ particularly, the supervisor-subordinate relationships, which are the dominant power relations in my work setting, might constrain me from delivering more effective performance. Critical social theory considers that "power is both personally experienced and structurally created", and every individual possesses power and possibilities for change. ${ }^{30}$ This theory provides us an essential value dimension to question the power in social relations, advocating the creation of a socially equitable and democratic environment via social and personal changes. ${ }^{30}$

As for me, although I may not disturb the dominant power relations in my workplace, I can make changes in my own practice. Critical social theory points out that personal change is closely linked with social change, which provides a sense of agency. ${ }^{30}$ I will continuously espouse the values of equality, respect, trust, and collaboration, internalizing these values in my daily work and interpersonal communication. I will engage in spreading these positive values in my department, at least let these be the dominating values within the nursing team. I will map some strategies, such as formulating ground rules for the discussion to guide nurses in the correct way and transforming the conflicts within a team into an opportunity for growth and learning, to promote effective team communication and avoid the reemergence of previous situations. ${ }^{36}$ When I plan to implement new 
changes or make an important decision, I will communicate with nurses at different levels or share necessary information with all staff through e-mail, bulletin boards, or other tools before team meetings, which is conducive for nurses to prepare their speeches for the meeting. ${ }^{25,37}$ Instead of paternalism, I should express more trust in the capabilities of nursing staff and motivate them to actively create. In addition, I will be an active and reflective listener during team communication, for instance, using nonverbal communication, such as eye contact, facial expressions, poses, and postures, to express my interest and motivate nurses to continually share their ideas; and making efforts to offer feedback, such as rephrasing or retelling nurses' words, to confirm that I understand their opinions correctly. ${ }^{38}$ Certainly, it is inevitable that disagreement might still occur in team meetings. I will make the decision according to the opinions of the majority and also have individual conversations after the meeting with those holding different views. I believe that with these strategies, we will achieve the desired outcomes in team communication, at the same time, embodying the values of equality, respect, trust, and collaboration during the process.

\section{Discussion}

An efficient and effective team communication is crucial for promoting mutual understanding and collaboration among nursing team members, consequently influencing the delivery of high-quality and safe patient care. ${ }^{39}$ In this paper, by reflecting on my own practice in the context of communication in a team, I have obtained a deep and broad understanding of my thoughts and actions. This type of critical emancipatory reflection helps me critically evaluate my performance and interpret my role and social obligation in my workplace, without being limited by taken-for-granted assumptions and oppressive forces. ${ }^{3}$ Through emancipatory reflection, I have realized that I endorse the ideas of

\section{References}

1. Somerville D, Keeling J. A practical approach to promote reflective practice within nursing. Nurs Times. 2004;100:42-45.

2. Taylor B. Technical, practical, and emancipatory reflection for practicing holistically. $J$ Holistic Nurs. 2004;22:73-84.

3. Taylor B. Reflective Practice for Healthcare Professionals. 3rd ed. Maidenhead: Open University Press. 2010.

4. Smyth J. Developing and sustaining critical reflection in teacher education. J Teacher Educ. 1989;40:2-9. equality, respect, trust, and collaboration, which I gradually formed and established during the process of professional socialization. However, I did not fully embody these values in my earlier practice, which even sometimes ran counter to these values. Another benefit of emancipatory reflection is to provide me the opportunities to identify issues, such as sociocultural, historical, political, and personal factors, which impede me from performing more effectively in terms of team communication and thereafter take actions to rectify these constraints in the future. Moreover, relevant theoretical perspectives of hegemony, socialization, and critical social theory are integrated into the processes of critical emancipatory reflection to help me make sense of my practice. To improve team communication, alternative actions should be implemented, for instance, formulating ground rules for discussion, guiding nurses in the correct way, transforming conflicts within a team, being an active and reflective listener, and motivating nurses to actively create.

\section{Conclusions}

The purpose of this paper is to reflect on my personal practice of team communication in order to gain a deep and broad understanding, as well as to improve the efficiency and effectiveness of team communication. This experience of critical reflection has been a rewarding lesson for me. Reflection is regarded as an effective way to obtain knowledge and develop a comprehensive understanding of practice. I realize that undertaking critical reflection is an integral part of the development of clinical nursing. Therefore, I will become a reflective practitioner, engaging in reflection on my practice in order to continuously improve my performance in the future.

\section{Conflicts of interest}

The author declares no conflicts of interest.
5. Gluyas H. Effective communication and teamwork promotes patient safety. Nurs Standard. 2015;29:50-57.

6. Walsh K, Jordan Z, Apolloni L. The problematic art of conversation: communication and health practice evolution. Pract Dev Health Care. 2009;8: 166-179.

7. Villagran MM, Baldwin PK. Healthcare team communication. In: Hamilton $\mathrm{H}$, Chou WS, eds. The Routledge Handbook of Language and Health Communication. Abingdon: Routledge. 2014;Ch.22. 
8. Garon M. Speaking up, being heard: registered nurses' perceptions of workplace communication. $J$ Nurs Manage. 2012;20:361-371.

9. Schjoedt L, Monsen E, Pearson A, Barnett T, Chrisman JJ. New venture and family business teams: understanding team formation, composition, behaviors, and performance. Entrepreneurship Theory Pract. 2013;37:1-15.

10. Tjosvold D, Wong AS, Chen NYF. Constructively managing conflicts in organizations. Annu Rev Organ Psychol Organ Behav. 2014;1:545-568.

11. Lash S. Power after hegemony cultural studies in mutation? Theory Cult Soc. 2007;24:55-78.

12. Vallas SP. The adventures of managerial hegemony: teamwork, ideology, and worker resistance. Soc Prob. 2003;50:204-225.

13. Ma L, Wang X, He X. Diagnosis on corporate culture and construction. In: Rau P, ed. Cross-Cultural Design Methods, Practice and Impact. Los Angeles: Springer. 2015:339-348.

14. Perrault E, McClelland R, Austin C, Sieppert J. Working together in collaborations: successful process factors for community collaboration. Admin Soc Work. 2011;35:282-298.

15. Rajesh JI, Suganthi L. The mediating role of interpersonal communication satisfaction between transformational leadership and followers' trust. Int J Bus Excellence. 2016;9:418-440.

16. Nancarrow SA, Booth A, Ariss S, Smith T, Enderby $P$, Roots A. Ten principles of good interdisciplinary team work. Hum Resour Health. 2013;11:1-11.

17. Lai PK, Lim PH. Concept of professional socialization in nursing. Int e-J Sci Med Educ. 2012;6:31-35. http:// web.imu.edu.my/ejournal/approved/7.Research_ Lai_p31-35.pdf. Accessed April 20, 2017.

18. Ilies R, Curşeu PL, Dimotakis N, Spitzmuller M. Leaders' emotional expressiveness and their behavioural and relational authenticity: effects on followers. Eur J Work Organ Psychol. 2013;22:4-14.

19. Duchscher JB. A process of becoming: the stages of new nursing graduate professional role transition. J Contin Educ Nurs. 2008;39:441-450.

20. Davies JM. Team communication in the operating room. Acta Anaesthesiol Scand. 2005; 49:898-901.

21. Fagerlin A, Zikmund-Fisher BJ, Ubel PA. Helping patients decide: ten steps to better risk communication. J Natl Cancer Inst. 2011;103:1436-1443.

22. Simon B. Respect, equality, and power: a social psychological perspective. Gruppe. Interaktion. Organisation. (Zeitschrift für Angewandte Organisationspsychologie). 2007;38:309-326.

23. Carter I. Respect and the basis of equality. Ethics. 2011;121:538-571.
24. Cribb A, Entwistle VA. Shared decision making: trade-offs between narrower and broader conceptions. Health Expectations. 2011;14:210-219.

25. Mesmer-Magnus JR, DeChurch LA. Information sharing and team performance: a meta-analysis. $J$ Appl Psychol. 2009;94:535-546.

26. Krabec T. Asset valuation standards: a functionalinstitutional approach. Prague Econ Papers. 2014;23:531-540.

27. Otter AD, Emmitt S. Exploring effectiveness of team communication: balancing synchronous and asynchronous communication in design teams. Eng Constr Archit Manage. 2007;14:408-419.

28. Farr-Wharton R, Brunetto Y, Shacklock K. Professionals' supervisor-subordinate relationships, autonomy and commitment in Australia: a leadermember exchange theory perspective. Int $\mathrm{J}$ Hum Resour Manage. 2011;22:3496-3512.

29. Ackroyd S, Kirkpatrick I, Walker RM. Public management reform in the UK and its consequences for professional organization: a comparative analysis. Public Admin. 2007;85:9-26.

30. Fook J, Gardner F. Practising Critical Reflection: A Resource Handbook: A Handbook. Berkshire: McGraw-Hill Education. 2007.

31. Bally JM. The role of nursing leadership in creating a mentoring culture in acute care environments. Nurs Econ. 2007;25:143-149.

32. Wang G, Oh IS, Courtright SH, Colbert AE. Transformational leadership and performance across criteria and levels: a meta-analytic review of 25 years of research. Group Organ Manage. 2011;36: 223-270.

33. Pellegrini EK, Scandura TA. Paternalistic leadership: a review and agenda for future research. $J$ Manage. 2008;34:566-593.

34. von Stamm B. Leadership for innovation: what you can do to create a culture conducive to innovation. Strategic Direction. 2009;25:13-15.

35. Feltner A, Mitchell B, Norris E, Wolfle C. Nurses' views on the characteristics of an effective leader. AORN J. 2008;87:363-372.

36. Hartman RL, Crume AL. Educating nursing students in team conflict communication. J Nurs Educ Pract. 2014;4:107-118.

37. Brock D, Abu-Rish E, Chiu CR, et al. Interprofessional education in team communication: working together to improve patient safety. BMJ Qual Safe. 2013;22:414-423.

38. Jalongo MR. Learning to Listen, Listening to Learn. Washington, DC: National Association for the Education of Young Children. 2008.

39. Gluyas H. Effective communication and teamwork promotes patient safety. Nurs Stand. 2015;29:50-57. 